\title{
PROTOCOLOS DE ENFERMAGEM: PROMOVENDO O ACESSO E QUALIDADE DA ASSISTÊNCIA NA ATENÇÃO PRIMÁRIAÀ SAÚDE
}

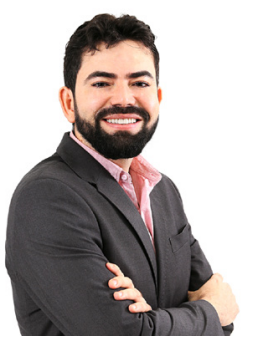

\author{
Carlos Leonardo Figueiredo Cunha ${ }^{1}$ \\ Professor Adjunto da Universidade Federal do Pará \\ (UFPA) \\ Editor Associado da Revista Enfermagem em Foco \\ Membro da Comissão de Práticas Avançadas em \\ Enfermagem do Conselho Federal de Enfermagem \\ (COFEN) \\ ORCID: 0000-0002-1891-4201
}

Atenção Primária à Saúde (APS), no Brasil é entendida como termo correlato à Atenção Básica, tem a Saúde da Família como estratégia prioritária e se constitui como a porta de entrada nos serviços de saúde frente as necessidades e problemáticas apresentadas pela população. É entendida como um nível de atenção, cuja as intervenções de saúde estão agrupadas em um conjunto organizado de medidas com tecnologias simples e de baixo custo, a fim de proporcionar promoção, prevenção, diagnóstico, tratamento e reabilitação ao indivíduo ${ }^{1}$.

Como membro da equipe mínima da Estratégia Saúde da Familia (juntamente com o médico, técnico ou auxiliar de enfermagem e agentes comunitários de saúde), o enfermeiro desenvolve atividades clinico- assistenciais, educativas e gerenciais, conforme suas atribuições dispostas na Portaria Ministerial/GM no 2.436/2017 que aprova a Política Nacional de Atenção Básica (PNAB) em consonância com a Lei 7.498/86 (Lei do Exercício Profissional de Enfermagem) e de seu Decreto Regulamentador no 94.406/87.

$\mathrm{Na}$ implementação e estruturação da APS no Brasil, a Enfermagem vem ocupando uma posição de destaque, adotando o uso de instrumentos que norteiam e qualificam a sua prática, como exemplo, os protocolos de enfermagem.

Nesse sentido, a estruturação e implementação de Protocolos de Enfermagem na APS justifica-se pelas diversidades culturais, sociais, epidemiológicas, demográficas, econômica, política e de cunho assistencial existente no nosso país. Somado a isto, o Ministério da Saúde emite constantemente normas, diretrizes, manuais como os Cadernos de Atenção Básica, dentre outros, no intuito de orientar o processo de trabalho e o cuidado em saúde, mas, muitas vezes não se torna claro e evidente, as competências técnicas e os limites de cada categoria profissional, nesses documentos ${ }^{2}$.

Para estruturação de um protocolo, recomenda-se definir previamente sua finalidade, público-alvo e elencar os principios éticos e legais que o norteiam. Outros aspectos também devem ser observados, tais como: sua validação, seu monitoramento e

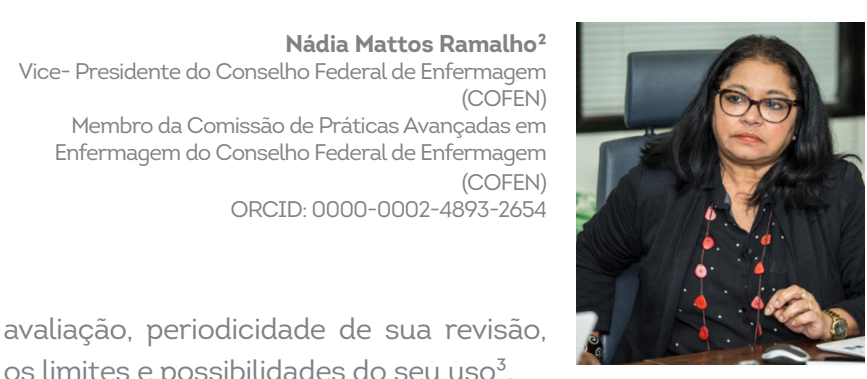

A adoção de protocolos promove maior segurança aos usuários e profissionais, estabelece limites de ação e cooperação entre os diversos profissionais, reduz a variabilidade do cuidado, norteia o profissional para a tomada da decisão assistencial, incorpora novas tecnologias, inova o cuidador e permite maior transparência e controle dos custos ${ }^{3}$

Diante deste contexto, no intuito de respaldar e assegurar as práticas dos enfermeiros no âmbito da atenção Básica no Brasil, o Conselho Federal de Enfermagem (COFEN) elaborou as Diretrizes para Elaboração de Protocolos de Enfermagem na Atenção Primária a Saúde, para implementação nos estados brasileiros, pelos Conselhos Regionais de Enfermagem (CORENs).

O projeto supracitado está sendo conduzido pela Comissão de Práticas Avançadas em Enfermagem (CPAE/Cofen), com colaboração da Câmara Técnica de Atenção Básica (CTAB/Cofen) e do Conselho Nacional de Secretários de Saúde (CONASS).

Para elaboração dos Protocolos de Enfermagem na APS, o projeto preconiza seis etapas: adesão, criação do Grupo de Trabalho (GT), elaboração dos protocolos, validação, publicação e divulgação. Foram instituídos dois atores com funções definidas para o apoio e condução do trabalho de elaboração dos protocolos pelo grupo condutor em cada Conselho Regional de Enfermagem: o Apoiador e o Facilitador. O perfil desejado para execução dessas funções são enfermeiros que tenham experiência prévia na elaboração e/ou aplicação de protocolos na APS e na condução de trabalho em grupo. O grupo de facilitadores foi constituído por $\mathrm{O} 2$ (dois) profissionais indicados pelos Corens que fizeram adesão ao projeto.

Com a implantação de Protocolos de Enfermagem, espera-se a ampliação do acesso aos usuários do SUS e o fortalecimento do papel da enfermagem na Atenção Primária à Saúde. 